This is an electronic reprint of the original article. This reprint may differ from the original in pagination and typographic detail.

Author(s): Ihalainen, Pasi; Palonen, Kari

Title: $\quad$ Parliamentary sources in the comparative study of conceptual history: methodological aspects and illustrations of a research proposal

Year: $\quad 2009$

Version:

Please cite the original version:

Ihalainen, P., \& Palonen, K. (2009). Parliamentary sources in the comparative study of conceptual history: methodological aspects and illustrations of a research proposal. Parliaments, Estates \& Representation, 29, 17-34.

All material supplied via JYX is protected by copyright and other intellectual property rights, and duplication or sale of all or part of any of the repository collections is not permitted, except that material may be duplicated by you for your research use or educational purposes in electronic or print form. You must obtain permission for any other use. Electronic or print copies may not be offered, whether for sale or otherwise to anyone who is not an authorised user. 


\section{Parliamentary sources in the comparative study of conceptual history: Methodological aspects and illustrations of a research proposal}

Pasi Ihalainen \& Kari Palonen, University of Jyväskylä

Alternative sources for the conceptual histories of political cultures

Historians and political theorists in Europe have been writing national histories of the use of key political concepts for nearly forty years. One of the reasons why the widespread call for writing comparative studies in conceptual history instead has seldom been answered lies in the limited number of sources for the past language of politics that could be directly compared both diachronically and synchronically. Another reason is the inherent tendency of history writing to focus on the study of the development of present-day nation-states.

The German Geschichtliche Grundbegriffe. Historisches Lexikon zur politischsozialen Sprache in Deutschland (GG), a comprehensive lexicon of political and social vocabulary initially published between 1972 and $1997,{ }^{1}$ has provided the principal model for writing histories of the formation of the meanings of key political concepts. The project was based on the use of an exemplary type of historical source, the Konversationslexikon, an originally eighteenth-century genre of mutually competing and frequently updated cultural encyclopaedias. Their easy availability allowed German scholars to demonstrate continuities and locate changes in the use and meanings of the key concepts selected for study. This approach to analyzing long-term conceptual change by using encyclopaedias was largely a consequence of German intellectual,

\footnotetext{
${ }^{1}$ Published in Stuttgart with Otto Brunner, Werner Conze and Reinhart Koselleck as the original editorial team. A Studienausgabe with a short new preface by Koselleck was published in 2004.
} 
literary and political culture in the eighteenth and nineteenth centuries; similar sources are not necessarily to be found in all political cultures of the period. In Germany, the encyclopaedias provided one of the few available media for free political and social debate. In other countries, however, encyclopaedias never achieved such a central role in public discourse, with the single obvious exception of the eighteenth-century Encyclopédie in France. As a consequence, it has not been possible for the Dutch, Spanish, Finnish and Swedish national projects in conceptual history to follow a similar research strategy in their analysis of the development of political and social discourse over time.

Lexicographical sources are, in fact, far from ideal for the study of the formation and change of political vocabularies in different countries. In most countries, the authors of such reference works were not themselves actively engaged in the politics of the day and thus did not necessarily possess up-to-date information about the state of political discourse. Although many of the German lexica were updated regularly, they do not necessarily take us to the very heart of past political debates. And we should be able to enter this in order to be able to reconstruct the spectrum of meanings which the key terms of such debates were given. We evidently need to investigate alternative types of primary sources for the past use of the language of politics.

One of the crucial insights of the GG project was Reinhart Koselleck's frequently mentioned Sattelzeit thesis, ${ }^{2}$ in which he connected the creation of lexicographical sources with the rethinking and reformulation of political and social concepts practiced by the editors of the Konversationslexika during the second half of the eighteenth and the first half of the nineteenth centuries, a period which he called Sattelzeit. According to Koselleck, the editors and authors found in their encyclopaedias

\footnotetext{
${ }^{2}$ See Koselleck's ,Einleitung', Geschichtliche Grundbegriffe, Bd. 1 (Stuttgart 1972), pp. xiii-xxviii.
} 
an important medium for public debate in the Germany of their time. The authors of the articles were frequently not content with establishing the conventional meaning of the term they were defining, but, aware of the ongoing intellectual change in the Ages of Enlightenment and Revolution, readily introduced a new, future-oriented dimension into their texts. To put it another way, in German-speaking Europe, the political agenda of the late eighteenth and early nineteenth centuries was to a great extent degree set by the lexica. These, in turn, were read and their ideas adopted by a variety of participants in the literary and debating public spheres. The Konversationslexika thus played a major role in the intellectual change that brought about the gradual breakdown of the old regime in nineteenth-century Germany, and the $G G$ set out to illustrate, among many other things, when and how this breakdown took place and was conceptualized.

The German encyclopaedias were a response to particularly German circumstances: they became an important genre for political debate because of the absence of parliamentary institutions and free elections in the formation and control of government in Germany. The prevalent political circumstances thus made the creation of alternative fora for political debate necessary. From the point of view of comparative conceptual history, however, this German model is not universally applicable. By contrast, countries with different kinds of representative institutions provide us with more direct access to the heart of the political debates even before the French Revolution. This is, of course, even more evident for nineteenth and twentieth-century Europe. However, none of the national projects outside Germany has yet exploited the possibility of using parliamentary debates as sources that constitute the actual basis of the study of conceptual history. One of our goals of this article is to reflect why this has been the case and what could be done to develop conceptual history by basing it more 
clearly on this type of source. At the same time, we wish to bring a new dimension to the study of political history and the rhetoric of parliamentary institutions.

The availability and obvious centrality of parliamentary sources in the political culture of several countries gives us reason to argue that these should be attributed a central role in the study of the history of key political concepts in the European context. Furthermore, we argue that parliamentary sources should be used in studies comparing the political cultures of various European countries. They should, of course, be supplemented with a variety of other archival and printed sources. However, we can justifiably suggest that parliamentary sources should form the starting point of this type of comparative study of political cultures.

Parliamentary institutions as a common European innovation

Representative institutions have a long history, going back to the Middle Ages in a number of European countries. Traditional, estate-based representative institutions (Landstände) also existed in some German states. In Sweden and the Dutch Republic, the traditional estates were partly reformed in the course of the eighteenth century, and the agenda of political debate began to be set by the representative institutions there. Extensive and reasonably reliable records of debates that took place in these institutions have survived, particularly in the case of Sweden. At times, these countries also enjoyed a considerable degree of freedom of publishing, which enabled the development of a dynamic relationship between debates that took place in representative institutions on the one hand and in published literature on the other. Some other European countries also had influential diets in the eighteenth century, but these countries either lacked free public discussion or their diets were less influential in the political system. 
In speaking about 'parliamentary' institutions in the strict, modern sense of the word, it is indispensable to turn to the historical model of the British Parliament, as it gradually developed as a distinct political institution from medieval times to the eighteenth century. The crucial point is to distinguish this deliberating parliament from ancient popular assemblies, medieval city assemblies based on guilds or corporations, as well as from the diets, whose decisions were still based primarily on inter-estate negotiations. The influence of the estates declined throughout Europe in the sixteenth and seventeenth centuries, but particularly the Swedish, Dutch and Polish Diets were regularly convened, and they also continued to play a principal political role during the eighteenth century. In what follows, we shall mainly discuss parliaments, although we shall also include occasional references to diets that allowed the expression of a multiplicity of views. In Sweden, for instance, some distinctly 'parliamentary' features of deliberation, debate and procedure were adopted in a traditional estate-based diet.

The distinction is a fluid one, of course; even the British Parliament was originally based on estates. In England, however, the clergy was quite early on incorporated into the nobility, and the House of Commons already differed in the late medieval times from European diets because of a crucial parliamentary principle - the free mandate of its members. ${ }^{3}$ In the struggle of Parliament with Tudor and Stuart monarchs in the sixteenth and seventeenth centuries, certain further 'freedoms' were demanded as indispensable 'privileges' of Parliament over the royal prerogative. An unpublished text from 1604, known as 'The Apology of the Commons', which was aimed at defending Parliament against the extending powers of the new king, James I, defends in rather modern terms free parliamentary elections, free speech in Parliament

\footnotetext{
${ }^{3}$ See, for example, Gaines Post, 'Plena potestas and Consent in Medieval Assemblies' [1943], Helmut Rausch, Die geschichtlichen Grundlagen der modernen Volksvertretung I (Darmstadt 1974), pp. 30-114 and Christoph Müller, Das imperative and freie Mandat (Leiden 1966).
} 
and freedom from arrest for members, a privilege later known as parliamentary immunity. ${ }^{4}$

It is arguable that some procedural principles, stemming from what Quentin Skinner ${ }^{5}$ has called Renaissance rhetorical culture, were central in the transformation of the British Parliament in the early modern period. By taking account of these, we can actualize the rhetorical dimension of parliamentary politics. The etymology of 'parliament' (derived from the Italian and French verbs parlare and parler ${ }^{6}$ ) also reveals the centrality of speaking in the institution. Parliament distinguished itself from the estates of the rest of Europe in that it was, already by the seventeenth century, not merely a representative but also a deliberative decision-making assembly. The debt of Parliament to Renaissance rhetoric is manifest in the procedural principle of dealing with every item on the parliamentary agenda from opposing points of view, pro et contra, with members speaking for and against a particular motion. In the course of the eighteenth and nineteenth centuries, the British Parliament attained a truly paradigmatic status as a deliberative assembly. Later on, it became the leading model for the organization of other kinds of assemblies and meetings on all levels. Seen from the rhetorical point of view, Parliament assumed an exemplary position as a site of deliberative rhetoric. It became an institution which no serious study of the history of political culture can ignore.

Some recent studies on the rhetorical political culture of the English Renaissance $^{7}$ are directly relevant for an understanding of Parliament as a deliberative

\footnotetext{
${ }^{4}$ The document is cited in: http://www.constitution.org/sech/sech 089.htm.

${ }^{5}$ Quentin Skinner, Reason and Rhetoric in the Philosophy of Hobbes (Cambridge: Cambridge University Press, 1996).

${ }^{6}$ See, for example, Kurt Kluxen, Geschichte und Problematik des Parlamentarismus (Frankfurt 1983).

${ }^{7}$ Besides Skinner's Reason and Rhetoric and the related essays in Vols. 2 and 3 of his Visions of Politics (Cambridge: Cambridge University Press, 1996), see also Peter Mack, Elizabethan Rhetoric: Theory and Practice (Cambridge: Cambridge University Press, 2002); David Colglough, Freedom of Speech in Early Stuart England (Cambridge: Cambridge University Press, 2005); Sylvia Adamson, Gavin Alexander \& Karin
} 
assembly. In contradistinction to the recently fashionable 'realist' studies in historical research and political science that distinguish between deeds (votes) and mere talk (speeches) in parliamentary studies and see Parliament as little more than a forum for political events, rhetorical studies accentuate the value of parliamentary debates and controversies independently of their final results. Emphasizing speaking as the major, if not the only, form of action available for members, rhetorical studies offer us a stimulating example of a re-reading of classical studies on parliamentary procedure. ${ }^{8}$ They make us more aware of the presence of rhetorical elements in Parliament: the three readings of a bill, the alternation of speeches pro et contra or the sanctioning of 'unparliamentary language'. The novelty of modern Parliament as an institution and of its procedures and practices is also manifested in the formation of a distinct parliamentary vocabulary, related to both the procedural technicalities and the principles of parliamentary deliberation and representation.

The recognition of these procedural principles strengthened the powers of Parliament in relation to the Crown and the ministry. It supported the regularization of parliamentary sessions on an annual basis and, later on in the eighteenth century, the gradual 'parliamentarization' of the government. This process included the emerging possibility that Parliament could, in principle at least, overthrow the ministry or at least have ministers dismissed by a vote of no-confidence. The most famous instances of this in Britain include Walpole's removal from office in 1742 and North's resignation in 1782. In Sweden, too, the procedure of licentiering (dismissal) of Senators, adopted in the Age of Liberty, produced several changes of ministries as a result of defeats by rival parties in the Riksdag. However, even in Britain, until the last decades of the nineteenth

Ettenhuber (eds), Renaissance Figures of Speech (Cambridge: Cambridge University Press, 2007), including Skinner's article on Paradiastole.

${ }^{8}$ See, for example, Josef Redlich, Recht und Technik des Englischen Parlamentarismus (Leipzig 1905) as one of the best-known classical works on the subject. 
century the ministry remained first and foremost an executive body nominated by the monarch rather than an organ that had developed into a government fully responsible to the parliament.

Should the focus be on public or parliamentary debates?

Our suggestion that parliamentary sources should provide the key dimension for the analysis of political discourse challenges the view that pre-political or extraparliamentary publicity has been the major primus motor of political change ever since the eighteenth century. This Habermasian paradigm, ${ }^{9}$ still widely held by scholars of eighteenth-century history and political sociologists and constantly reiterated in various studies, has contributed to the neglect and even contempt for parliaments, politicians and the rhetorical culture of parliamentary speaking in much existing scholarship. This practice ignores the central role which parliamentary speaking had played in the political life of several northern European countries ever since the Middle Ages - a role that the contemporaries appreciated and one that historians should likewise appreciate. Habermas' vision is better fitted to polite discussions in clubs and salons than to the parliamentary procedure of speaking pro et contra.

In recent decades, the role of the press in providing an alternative forum for political enlightenment has thus possibly been overemphasized in eighteenth-century studies. These studies, though illuminating in many ways on the rise of publicity, have tended to ignore any closer analysis of parliamentary records. ${ }^{10}$ In the comparative

\footnotetext{
${ }^{9}$ Originally presented in Jürgen Habermas, Strukturwandel der Öffentlichkeit (Neuwied 1962).

${ }^{10}$ See John Brewer, Party Ideology and Popular Politics at the Accession of George III (Cambridge: Cambridge University Press, 1976); Kathleen Wilson, The Sense of the People: Politics, Culture, and Imperialism in England, 1715-1785 (Cambridge: Cambridge University Press, 1995); Marie-Christine Skuncke, 'Den svenska demokratidebatten 1766-1772', Rut Boström Andersson (ed.), Ordets makt och tankens frihet. Om språket som maktfaktor (Uppsala 1999), pp. 283-94; Hannah Barker and Simon Burrows, 'Introduction', Hannah Barker and
} 
study of political concepts, the a priori division into political history and the history of political thought is also outdated regarding primary sources, and the potentially creative conceptual role of parliamentary debates deserves to be acknowledged. A combined study of parliamentary records and published literature might, therefore, provide the most balanced account of how politics was understood by various echelons of the political and intellectual establishment.

The tendency to stress the role of the public sphere in political discourse, though understandable as a result of the novelty of the phenomenon in comparison with parliaments, may in fact be misleading as far as the history of political concepts is concerned. Jeremy Black, a scholar who has studied both Parliament and the press in the eighteenth century, has pointed out that in Britain - and to a great extent also in Sweden and the Netherlands, we might add - the agenda of the public debate was set by parliaments and diets rather than by the press. Whereas it is quite clear that parliamentary debates were part of the decision-making process, the influence of the press debates on political decisions remains far from evident. The purpose of the parliamentary debates was not only to communicate the views of the people to the government but also to allow diverging opinions within the government to be expressed. Black has summarized his interpretation of the importance of Parliament as follows:

Parliament was important not so much as a forum where government could be defeated, a relatively rare occurrence, but as one that encouraged a change in the nature of political debate, by creating a regular agency for publicly representing political views.

Simon Burrows (eds.), Press, Politics and the Public Sphere in Europe and North America, 1760-1820 (Cambridge: Cambridge University Press, 2002), pp. 1-22; Hannah Barker, 'England, 1760-1815', Ibid., pp. 93112. These are all excellent and helpful analyses of public discourse, but the point we are making here is that we should instead examine, and even to concentrate on, parliamentary debates. 
As Parliament was the public forum in which the ministry formally presented and defended its policy and was criticized in a fashion that obliged it to reply, it was Parliament where the public debate over policy can be seen as most intense and effective. There was an obligation to respond that was lacking in the world of print, and an immediate linkage between the debates and the taking of decisions, the debates themselves being occasioned by the discussion of these very decisions. $^{11}$

Following Black, we would like to argue that the existence of continual parliamentary debates in itself supported change in political language and culture by providing a forum for the expression of political opinions through the use of language and concepts. Arguments for and against a particular motion inevitably revealed differing conceptualizations of the political reality among the members. Even in Britain, the arguments that were presented did not always match the division between the government and the opposition but could also reflect disagreements within the two groups. Irrespective of the differences in their opinions, all sides were obliged to present their points of view clearly and, consequently, the central political concepts of the day entered the debates. This use of concepts was part of the rhetorical character of parliamentary deliberations and could really affect the decision-making process; the concepts did not merely reflect some external 'political reality'. In present-day historical research, these parliamentary speech acts thus need to be taken as important objects of analysis.

\footnotetext{
${ }^{11}$ Jeremy Black, Eighteenth-Century Britain 1688-1783 (London 2001), pp. 217-221; see also Jeremy Black, Parliament and Foreign Policy in the Eighteenth Century (Cambridge: Cambridge University Press, 2004), pp. 1, 6-7.
} 
Black has seen the British Parliament as a functioning forum of leading political debate. According to him, its status in the polity, despite the oligarchic restrictions on parliamentary influence, was unique and not comparable with other eighteenth-century national representative bodies. The Swedish Estates, the Dutch Estates General and the Polish Diet, for instance, were all subject to conflicts, delays and a loss of status at some time in the course of the century. No other representative assembly was equally admired at home and abroad, by contemporaries and later historians, as was the British Parliament, Black maintains. $^{12}$

However, Black's admiration for the uniqueness of the British Parliament as a forum of intense political debate is perhaps exaggerated. Other eighteenth-century representative assemblies also played key roles in political life and have - at least in the case of Sweden and the Batavian Republic in the late 1790s - produced records on parliamentary debates that are eminently suitable for the comparative study of the conceptual history of parliamentarism. In Sweden in the 'Age of Liberty' (1719-1772), the Riksdag was the leading forum of political debate during its sessions, particularly as no unregulated public debate was allowed in the country before 1766 . The Diet was a place in which information was obtained and distributed and where the representatives formulated and articulated opinions in order to influence the members of their own and the other estates. It was also a forum where not only legislative but to some extent also executive decisions were made. It produced a mass of very detailed records, including discussion minutes which are comparable with the British reports and undeniably the most complete records we have from any eighteenth-century representative body. ${ }^{13} \mathrm{~A}$ major difference from parliamentary procedure in Britain was, of course, the fact that decisions were based on negotiations between the estates and not by a counting of votes

\footnotetext{
${ }^{12}$ Black, Eighteenth-Century Britain, pp. 217-18.

${ }^{13}$ Cf. Willibald Steinmetz, Das Sagbare und das Machbare. Zum Wandel politischer Handlungsspielräume in England 1780-1867 (Stuttgart 1993), p. 45, who also sees the British debates as unique.
} 
in a unified parliament. The presence of four estates and their joint committees made the number of debates - and hence the extant records - very high.

In parliamentary debates, we can identify the precise types of actual speaking situations in which the key political concepts of the time were used. We can easily find the responses of the other speakers and draw conclusions about what kinds of conceptual choices were generally acceptable to the participants and what aroused criticism. In that way, we can demonstrate the range of possible meanings that could be assigned to a particular concept by the parliamentarians.

Particularly in the case of the British Parliament, with its tradition of constantly speaking pro et contra in a competitive atmosphere, the distinctions between the opposite sides could be very clear, and these are reflected in conceptual choices. We can also locate intentional innovative speech acts that constituted changes in the meanings of the concepts. The choice of words frequently corresponded to changing modes of speaking among the political establishment. And even if the speakers merely aimed at using a concept in a way that could be shared by their audience, doing so might involve conceptual modifications.

To supplement the analysis of parliamentary debates, we need to study other fora of public debate - particularly those directly connected with current debates in Parliament. This kind of contextualization ensures that we take account of a wider range of the meanings or rhetorical connotations assigned to the concepts in different speaking situations at the studied time. As Black has reminded us, 'public opinion' did not explain the policy which eighteenth-century governments followed, but it did provide a forum for the expression of a further plurality of opinions (and hence further uses of political concepts), and it also increased nationwide political awareness of such opinions. Importantly, parliamentary reporting became, after the 1770 s at the latest, a 
regular part of these public debates in the British press. ${ }^{14}$ This reporting linked Parliament and the other public fora and led to what Charles Tilly has seen as the increasing parliamentarization of popular politics. ${ }^{15}$

During the late eighteenth century, there was an increasing interaction between parliamentary deliberations and extra-parliamentary public debates in Britain. The gallery of the House of Commons was open to a limited audience, and newspapers reported parliamentary debates actively, and from 1770 on with increasing accuracy. In Sweden, the secrecy of the proceedings of the Riksdag was broken during the heated debates of the late 1760 s when pre-publication censorship was relaxed. In the case of the Batavian Republic, the openness of the representative body was enhanced by the fact that its regulations ordained that it should assemble with open doors whenever possible. Parliamentary proceedings and public debate were directly linked by the publication of detailed records of debates in the national assembly just days after they took place. ${ }^{16}$ The interaction between parliamentary and public debates thus evidently increased in the eighteenth century.

Parliamentary vocabularies

The rhetorical and conceptual aspects of parliamentary speaking clearly deserve particular attention. In the course of the early modern period, speaking in Parliament had also become a sine qua non for the career prospects of leading politicians. From the point of view of comparative conceptual history, parliamentary speaking produced valuable sources in that it gave rise to a number of cases of the recycling of

\footnotetext{
${ }^{14}$ Black, Eighteenth-Century Britain, pp. 225-6.

${ }^{15}$ See Charles Tilly, 'Parliamentarization of Popular Contention in Great Britain, 1758-1834', Theory and Society 26, 1997, pp. 245-73.

${ }^{16}$ Leonard de Gou, Het Ontwerp van Constitutie van 1797: de behandeling van het Plan van Constitutie in de Nationale Vergadering ('s-Gravenhage 1983), pp. xi, xix, xxvi, xxviii, xliv.
} 
conventional concepts in generally shared senses and innovative speech acts aimed at altering the political content or connotations of a concept. In parliamentary speaking, as practised in countries such as Britain and Sweden, the emerging principles of the codification of the parliamentary procedure were combined with conventional precepts provided by classical and Renaissance rhetoric. ${ }^{17}$

One consequence of all this was that a distinct genre called by the contemporaries 'parliamentary eloquence' or 'parliamentary oratory ${ }^{18}$ was being formed and receiving conceptual expression in Britain in the course of the eighteenth century. In the literature on rhetoric, parliamentary debate slowly superseded the ancient examples as the paradigm of the genre of deliberative rhetoric.

Parliament also gave birth to an entirely new political vocabulary. The meanings of many key parliamentary concepts were controversial and contested from their very beginning, which makes them worth a closer study from the perspective of conceptual history. Concepts such as 'parliament', 'assembly', 'chamber', 'house', 'representation', 'mandate', 'deliberation', ‘debate', ‘negotiation', ‘vote', ‘majority', ‘minority’, 'compromise', 'motion', 'question', 'closure', 'speaker', 'plenum' and 'committee' as well as the names of the parliamentary parties and, after the French Revolution, the denominations 'Left', 'Right' and 'Centre' exemplify conceptualizations of a distinctly parliamentary type of political culture. All of these terms appeared in a wide variety of senses in different parliaments, and their meanings also went through major transformations in individual countries. What is more, the use of all of them has been

\footnotetext{
${ }^{17}$ See the references to ancient rhetoricians in William Gerard Hamilton's posthumously (1808) published Parliamentary Logick, consisting of maxims collected as a member of British Parliament from 1754-96, edited by Courtney S. Kenny (Cambridge 1927).

18 'Parliamentary rhetoric' was hardly used in the English and French literature. For differing interpretations of the notions of 'eloquence' and 'oratory' from an early-twentieth-century perspective, see Earl Curzon of Kedleston, Modern Parliamentary Eloquence (London 1913) and James Johnston, Westminster Voices (London 1927).
} 
extended from parliaments to a number of other representative institutions and political organizations that may otherwise differ considerably from parliaments.

Our key argument in this article is that the conceptual history of parliamentary politics understood in this broad sense - combining the study of the aspects of procedure, regime and rhetoric - still remains to be written. The possibilities for writing such a conceptual history of parliamentary politics exist, and it is likely to shed new light on the formation and present-day character of modern parliamentary regimes as well. At the same time, it may offer corrections and reinterpretations for histories of concepts which have been written on the basis of different types of sources. It will certainly lead to reconsiderations of the relative roles of parliamentary institutions and the public debate in the formation of modern political cultures as well as to the reactivation of parliamentary deliberations in contemporary rhetorical studies.

In arguing in favour of writing the conceptual history of parliamentarism, we are also aware of the methodological challenges involved. Careful contextualization and the consideration of specific institutional features are needed in using sources produced by seemingly parliamentary regimes that were not yet based on any democratic franchise. Moreover, the risks of anachronisms and teleological interpretations may increase if the contemporary use of language is not sufficiently taken into account. At the same time, these risks are even greater in a historiography of parliamentarism that does not adopt a consciously diachronic linguistic approach to the past but applies present-day analytical vocabulary to the study of early modern institutions.

In accentuating the 'parliamentary' elements of institutions, procedures and practices, we can recognize the historical singularity of parliaments which is largely lost today, when parliamentary politics is experienced as a routine part of the government vs. opposition division. We can focus on the rhetorical principles implicitly 
incorporated in the procedural aspects of parliaments, which have changed relatively little in the course of time. These principles have, furthermore, been widely adopted by parliaments that have been created much later and also by non-parliamentary polities such as the United States. ${ }^{19}$ For instance, every political system with representative government, has a regular parliamentary calendar with regular types of items and their ordering in time.

The availability of sources on parliamentary debates

The availability of sources sets limits to the study of the conceptual history of parliamentary politics in earlier periods. When we come to the eighteenth century, however, the source situation turns out to be quite good. Official records of plenary and committee debates and of all the documents submitted to the Swedish Diet exist in manuscript form from the eighteenth century on, and some even earlier records are also available. The publication of debates in printed form became a regular procedure in revolutionary France. In the Netherlands, the creation of a national assembly for the Batavian Republic after the French occupation also gave rise to semi-official reporting following the French model after 1796. The British case is more challenging. The unofficial British records after the sixteenth century are far from being verbatim reports of the debates, but they can still be fruitfully used in studies of political history, political thought and the comparative conceptual history of parliamentary politics.

Whatever the form in which parliamentary speaking was recorded - whether it was a newspaper report, a separately published pamphlet or, later on, a stenographic record and 'live' documentation - the records are inevitably imperfect but nevertheless

\footnotetext{
${ }^{19}$ The most famous model is Robert Rules of Order, created by the US General Henry M. Robert in 1876. See for example the 1915 edition at: http://www.bartleby.com/176.
} 
always useful. Indeed, the differences in the reporting as such can become one of the objects of interest for a conceptual history of parliamentary politics. Differences in records can reveal differing ways of conceptualizing political issues - that is politically crucial ideological distinctions - which need to be observed in the analysis of parliamentary politics. In the British case, for instance, different printed versions of the same eighteenth-century parliamentary speech demonstrate variation in how the same argument could be expressed by the speaker (if he had a version of his speech printed) and the different reporters.

Despite differences and transformations in the forms and practices of recording, the records of parliaments and diets constitute an extensive source for the genre of parliamentary speaking. A growing number of these sources are now more readily available and easier to use in analyses of political language, existing in a digitalized form searchable by full-text search engines. The search engines only help in finding the significant debates, of course; these still need to be contextualized and analyzed in detail by the scholar. This analysis of parliamentary speaking calls for an awareness of the special characteristics of the genre, including differences between speaking in Parliament and in other fora such as 'pulpit, bar and platform'. ${ }^{20}$

Parliamentary debates had some special features which support the use of the records in long chronological series for comparisons - both within a single political culture and between different political cultures. Among these features is the existence of regular parliamentary events such as the annual Speeches from the Throne at the opening of the British Parliament and the related debates and Addresses of Thanks of the two Houses, for instance. The speeches of His Royal Majesty and the speakers of the four estates in Sweden, as well as the related parliamentary sermons, at the opening

\footnotetext{
${ }^{20}$ For this triad see, for example, Joseph S. Meisel, Public Speech and the Culture of Public Life in the Age of Gladstone (New York 2001).
} 
and closure of every Riksdag also make long-term comparisons relatively easy to carry out. ${ }^{21}$ Budget debates, too, may allow long-term comparisons both within one parliament and between parliaments as the financial power of the British Parliament and the Swedish Estates was considerable from the eighteenth century on.

The nature of these debates has immediate consequences for the use of parliamentary records as sources for conceptual history. Regularly recurring parliamentary events, such as debates on Addresses to the monarch and budget debates, offered occasions for general discussions on the policy of the government. In other words, their subject was not so strictly regulated as those of ordinary debates. Such debates could lead to considerable confrontations, especially when the government and the opposition disagreed on constitutional issues or when the approval of the budget constituted the primary source of power for the parliament in polities that were not yet based on the full responsibility of the ministry to parliament. The annual budget debates and other regular events can be used to analyze the more latent and implicit changes in the conceptualization of politics, changes that often went unnoticed even among the contemporaries themselves. It is then the job of the historian to reconstruct the series of sources, to analyze it in a long-term perspective and to point out potential moments of conceptual change - such as that which followed defeat in the battle of Yorktown in the British Parliament in 1781 or the radicalization of the French Revolution, for instance. ${ }^{22}$

Such series of sources make it possible to date speech acts and conceptual innovations with greater precision and to analyze them in more concrete contexts of decision-making than the predominantly lexicographical sources used in Geschichtliche Grundbegriffe or the published literature used in the study of the rise of the public

\footnotetext{
${ }^{21}$ Pasi Ihalainen, Protestant Nations Redefined: Changing Perceptions of National Identity in the Rhetoric of the English, Dutch and Swedish Public Churches, 1685-1772 (Leiden 2005).

${ }^{22}$ Pasi Ihalainen, Agents of the People: Democracy and Popular Sovereignty in British and Swedish Parliamentary and Public Debates, 1734-1800 (forthcoming in Leiden 2009).
} 
sphere. In parliamentary debates, the reasons behind innovative speech acts are relatively easy to determine as the constant debate for and against inevitably revealed where the points of disagreement between the ministry and the opposition or within these groups lay. As a consequence, the future-orientation typical of German lexicographical sources can be complemented by relating conceptual changes to the constant political shifts in parliamentary majorities and governments. Parliamentary debates provided numerous opportunities for recalling past forms of argumentative discourse as well, which means that, instead of constant revision, earlier arguments tended to be recycled. Once recording became more regular, so did references to what had been previously argued in the same chamber.

At first sight, the records of parliamentary debates may seem to be tiresomely repetitive, lacking the kind of dramatic changes that any historian would like to find in his or her research material. However, parliamentary debates, when studied in large quantities and in the long term, constitute a rich source for the study of conceptual revisions in determinable political contexts. Conversely, short-term conceptual changes of major political significance can be detected by analyzing seemingly minor alterations in the vocabulary or shifts in the rhetorical connotations of concepts.

In studies on political thought, innovations have mainly been found in the texts of leading political theorists or located by mere chance in historical documents. Many conceptual transformations have not been recognized at all because of the sheer amount of source material available or reading strategies which have focused on individual speeches or seemingly relevant arguments rather than on a systematic analysis of the exact choices of words of the speakers, of debates as entities and of reconstructed series of regular speech acts. 
Let us consider the example of Speeches from the Throne in the British Parliament in more detail. ${ }^{23}$ The opening speeches of the King (in practice the ministry) and the Addresses of Thanks of the two Houses of Parliament constitute an unusually uniform series of speech acts within the otherwise more varied and spontaneous parliamentary debates. Including as they do every session of the Westminster Parliament, they enable the study of long-term continuities and changes in the official formulations of the political role of the people. The speeches were formulated by the ministry and the Addresses by leading members of the government party - after a proposal, a possibly heated discussion and sometimes attempted amendments. They represent the negotiated views of the political groups at large. They were, to be sure, influenced by a number of general-political, party-political and personal-political contexts and considerations, which need to be taken into account.

It is arguable that these carefully considered and mutually negotiated official documents convey what the majority of the British parliamentary establishment, or at least the governing coalition, considered to be the most relevant political arguments and the most proper political vocabulary to express them in on each occasion. They are particularly revealing with regard to the constitutional relationship between the monarch, the ministry, Parliament and the people. When read together, the Royal Speeches and the Addresses create a series of sources that enables the study of semantic change in references to the people from a genuinely macro-level perspective. An overall analysis of the vocabulary referring to 'the people' as used at the opening of Parliament provides a necessary counter-balance to the more micro-level analyses of the uses of the concept in individual parliamentary debates. Together, these two ways of reading

\footnotetext{
${ }^{23}$ For a more extensive discussion of this group of sources, see Ihalainen 2009.
} 
parliamentary debates make for a more balanced account of conceptual change, taking both groups and individuals into account.

Both in the Royal Speeches and in the official Addresses of Thanks of the two Houses, the different 'elements' of the British constitution were speaking in their constitutional roles, searching for ways to express their mutual relationships in a manner acceptable to all sides. This was, indeed, the only occasion when the monarch - or his ministry who had written the speech - and the representatives of 'the people' (or, in Aristotelian terms, 'aristocracy' and 'democracy') officially met and communicated with each other. While the Speeches and Addresses often appear to be repetitive and seem to lack sudden and unconventional changes, times of crisis did bring about considerable changes in their content and connotations, including the frequency, applications and particularly meanings of the vocabulary referring to the people. The ministry could use different strategies to persuade Parliament, either regarding it as itself constituting 'the people', or even regarding 'the people' as separate from Parliament, while the two houses looked for appropriate ways to express the loyalty of the people and sometimes also to assert the role of Parliament and the people as a political agent independent of the monarchy. Some opposition members might also suggest that the voice of the people and that of Parliament did not agree in the first place.

The Speeches and Addresses were thus used effectively to communicate messages to the other elements of the constitution. This becomes apparent when the statements of both sides are read in long-term series. The ministry was likely to appeal to 'the people' in different degrees and ways depending on its position at the time of the opening of the session. The House of Lords was usually cautious in all of its formulations, seeing itself as the major bulwark of the monarchy, but the House of 
Commons did occasionally send implicit (and at times actually quite explicit) messages to the monarch and the ministry in order to reassert its own constitutional role. A considerably amount of diversity in the responses can be found in the Commons debates on the Addresses of Thanks.

The intensity and length of the debates in both Houses can also be considered an indicator of the state of crisis existing at the time of the opening of each session. During the debates on the Address of Thanks, the members seem to have been free to discuss any issue however loosely related to the Royal Speech. This differs from the practice of normal debates, which had more clearly defined subjects, and makes the ceremonial speeches worthy of particular attention. Most importantly, the debates on the Addresses of Thanks provided opportunities for dissenting views on the political role of the people to be voiced. Furthermore, as the debates took place on the day of the opening of the session, every seventh year after general elections some members, having just have returned from their constituencies may have been especially ready to give expression to their constituents' views, collected during their election campaigns.

Rhetoric and conceptual change

Some contemporary eighteenth-century sources may also help us to locate conceptual innovations within parliamentary debates. A striking theme in William Gerard Hamilton's maxims, ${ }^{24}$ based on the speaking practices of the British Parliament during the second half of the eighteenth century, is the use of conceptual modification as a rhetorical tool in parliamentary debates. One strategy Hamilton introduced is the trope of paradiastole for the devaluation of virtues and attenuation of vices. Hamilton's

\footnotetext{
${ }^{24}$ See note 17.
} 
contemporary remarks as such suggest that parliamentary debates served as occasions for conscious conceptual revisions and innovations.

Conceptual changes could take place quite independently of which side actually won the division. They deserve close attention from conceptual historians, more particularly because remarks of less import may have been passed over in much previous history writing about parliaments. If carrying out pre-planned conceptual changes was already a central feature of parliamentary speaking in the eighteenth century, we can assume that such revisions became even more prevalent with the increasingly competitive nature of politics as strictly parliamentary regimes and democratic parliaments emerged from the late nineteenth century onwards. By that time, speaking had become an indispensable arena for politicking for every member, and the speeches became more spontaneous in order to catch 'the mood of the moment,' as Gladstone put it. ${ }^{25}$ This created numerous occasions for innovations in the meanings or connotations of concepts or the vocabulary used to express them.

To put our point another way, there is a risk that conceptual changes, which are not necessarily directly linked to political shifts and can take place in seemingly irrelevant debates, may go unnoticed in the ocean of parliamentary records. These conceptual changes can only be located and made objects of analysis when special attention is paid to them. The potentially creative uses of concepts can be more easily located among the great number of debates by using searches in digitalized records. They can also be contextualized more effectively in each particular debate. This research strategy can reveal conceptual innovations that help us to understand the development of a particular political culture or several political cultures that have been taken as objects of comparison.

\footnotetext{
${ }^{25}$ William E. Gladstone, 'Public Speaking', ed. by Loren Reid, The Quarterly Journal of Speech 39, 1953, 26672 (originally written in 1838).
} 
The slow and the rapid, the accidental and the intentional forms of conceptual change thus become equally analyzable through parliamentary records. Similarities and differences between parliamentary procedures and practices in different countries also permit comparisons between similar occasions in various parliaments at about the same time or in parallel periods in relation to some major parliamentary reforms. These reforms include debates on the mandates of the members in Sweden and Britain in the eighteenth century, the relationship of the Estates or Parliament to publicity outside the representative institutions, the early parliamentarization of government in connection with changes of ministries and, later on in the nineteenth and twentieth centuries, the gradual democratization of the franchise.

We can, for example, compare conceptualizations of the acceptance of, and the resistance to, the increasing professionalization of members of parliament into full-time politicians in different times and parliaments. The practical acceptance of professionalization and the corresponding transition to monthly salaries has taken place in the course of the twentieth century, but even contemporary debates on increasing the parliamentarians' salaries tend to give rise to a violent polemic against full-time politicians, even though no-one any longer seriously proposes a parliament without any compensation for its members, like Otto von Bismarck's vision of the Reichstag. ${ }^{26}$

A further aspect of inter-parliamentary comparison that deserves attention in the conceptual history of parliamentary politics is the translation and transmission of political vocabulary. Any example of the reception and mutual reflection of political vocabulary may be of interest, but the vocabulary distinctive of parliamentary polities deserves particular attention. We can easily analyze the history of language related to the adoption of the concept of the responsibility of the ministry and of individual

\footnotetext{
${ }^{26}$ For the debate between Bismarck and his opponents in the Reichstag after 1867, see for example Hermann Butzer, Diäten und Freifahrt im deutschen Reichstag (Düsseldorf 1998).
} 
ministers to parliament in a number of countries. We can also analyze the differing linguistic and conceptual resources of the languages spoken in various representative institutions as well as the problems of the translinguistic reception and modification of the international parliamentary vocabulary. Why was 'democracy', for instance, translated as 'power of the people', folksregering and Volksregeering in various political cultures? When was the classical, pejorative conception of 'democracy' replaced by a future-oriented, positive one in different political cultures? Debates on the possibility of the adoption of the compensation, and later on full-time payment, of the members of parliament in different countries constitute another area that is likely to reveal interesting linguistic and national variations.

The above-mentioned examples illustrate some of the specific issues involved in using parliamentary sources for the study of conceptual changes from a comparative perspective. We would like to suggest that historians, political scientists, jurists, linguists and other scholars of political cultures from a number of countries should cooperate in studying conceptual history on the basis of parliamentary sources. A number of areas deserve further attention in this field: some scholars could focus on the theoretical and methodological problems involved in the analysis of the distinctive character of parliamentary speaking; some could consider the theoretical and sourcecritical problems involved in short- and long-term intra- and inter-parliamentary comparisons, including differences in ways of keeping records. Equally important would be empirical case studies of conceptual history based on parliamentary sources, preferably with a theoretical and methodological discussion linked to the empirical analysis. The unifying feature of such international research cooperation would be the analysis of conceptual changes based on parliamentary sources. 
Assessment of the suggested change in research strategy

What kind of changes would the suggested research strategy entail for writing the history of parliaments and political cultures? Following Reinhart Koselleck's thesis on the Umschreibung der Geschichte, we can speak of three kinds of innovations in history writing: ‘neue Zeugnisse, neue Fragen, neue Interpretationen' (new evidence, new questions, new interpretations). ${ }^{27}$ How can we assess our proposal for a comparative conceptual history of parliamentary politics with respect to these three dimensions?

It is evident that as a result of our suggested assignment of a paradigmatic role to 'parliamentary sources' in research, Koselleck's first dimension would play a prominent role. The official and unofficial documentation of parliamentary debates and other materials presented in representative organs constitutes a 'material' basis for analyzing the use of political concepts in the past. More particularly, regularly recurring debates have taken place from at least the early eighteenth century to the present day, and most of these debates have been well documented. The gradual institutionalization of the documentation itself provides a basis for the comparison of documents. The comparison may take different forms depending on the criteria imposed by the research. The abundance of records that have not been very widely used in previous research is evident.

It is equally evident that the use of parliamentary sources creates new questions for conceptual history and the history of political cultures more generally. For conceptual history, focusing as it does mainly on the analysis of contested and controversial concepts, the value of parliamentary debate as sources is obvious. Indeed, for such research, parliamentary sources constitute a true paradigm for political debates.

\footnotetext{
${ }^{27}$ Reinhart Koselleck, Zeitschichten (Frankfurt 2000), pp. 50-51.
} 
In parliaments, debates are not merely something that arise by chance every now and then. On the contrary, deliberations pro et contra are not merely constantly conducted in parliaments but constitute the very essence of parliamentary politics, and they are, accordingly, built into parliamentary procedure. Parliamentary debate is also characterized by a number of regular and institutionalized occasions, such as the speeches at the opening sessions, budget debates, the installation of governments, interpellations, questions, etc. The novel procedure that we are suggesting here is that debates be analyzed from the point of view of conceptual moves, innovations, interventions, references back to earlier examples and comparisons with other contexts or with other parliaments. Particularly interesting are, of course, any contemporary comparisons with other political systems which the politicians themselves make in their speeches. These were already a regular feature of parliamentary and estate debates in Britain and Sweden in the eighteenth century. If past politicians actively compared different countries in order to make political points, why should not we do so too?

Finally, the systematic study of parliamentary sources is likely to create new interpretations in conceptual history and the history of political cultures more generally, leading to the re-dating of some major conceptual shifts. For example, not every political concept changed only with the advent of the American and French revolutions, as conventional history writing frequently suggests; a much more gradual process of transformation in which parliamentary institutions were involved may be discernible. ${ }^{28}$

Taking Koselleck's work as our point of departure, we would like to suggest that the history of parliamentary sources would offer different perspectives on his 'hypotheses' concerning the democratization, politicization and temporalization of concepts from the late eighteenth-century onwards. Koselleck used all three concepts in

\footnotetext{
${ }^{28}$ See Ihalainen 2009.
} 
a highly abstract way, disconnected from the institutions and practices of everyday politics. Without denying the merits of Koselleck's approach, we would like to suggest that parliamentary debates offer a different, and in a sense more specific and concrete, vision of the same phenomenon of conceptual change. The parliamentarization of government and the democratization of parliament - which took place with very different rhythms in different European countries - can be analyzed by using parliamentary debates, to quote Koselleck again, both as 'indicators' and 'factors' of conceptual changes, viz. 'democratization' and 'parliamentarization'. The politicization of each current issue is a key item on the parliamentary agenda, as is the revision of the character of this agenda itself. Parliamentary rhetoric operates, however, with a different time orientation from the Koselleckian unilinear view of temporalization in terms of progress and acceleration. Characteristic of parliamentary rhetoric is playing with time politically in terms such as ruptures, moments, time-spans and calendars. ${ }^{29}$

In addition, we can set a further task for the conceptual history of parliamentary politics, namely the formation of a distinct set of 'parliamentary concepts'. Their specific histories concern not only their coinage but also the political context of their use. The time of the introduction of a new term may be worth a closer conceptual historical examination. We can start by distinguishing the vocabulary of parliamentary procedure, including such expressions as 'petition', 'bill', 'motion', 'plenum', 'committee', 'session' and 'sitting'. The context is definitely crucial in the case of some technical innovations, for example clotûre and guillotine as nineteenth-century innovations to combat obstruction by members. They are not understandable without the key political concepts of the parliamentary regimes such as 'parliament',

\footnotetext{
${ }^{29}$ For a closer discussion of these concepts, see Kari Palonen, The Politics of Limited Times: The Rhetoric of Political Judgment in Parliamentary Democracies (Baden-Baden 2008).
} 
'assembly', 'representation', 'mandate', 'party', 'election', 'deliberation', 'debate', 'vote' and 'vote of no-confidence'.

We have characterized here a field of research that opens possibilities for innovative approaches to the history of parliamentary institutions. We welcome criticism and contributions from interested scholars and hope to be able to integrate them into the proposed project. Parliamentary debates need to be made a central topic of the history of political cultures and concepts. 